\title{
CALCULATION OF SOLID-LIQUID EQUILIBRIA USING THE MODIFIED BWR EQUATION OF STATE OF LEE AND KESLER
}

\author{
HiROKATSU MASUOKA, RYOZO TAWARAYA \\ AND SHOZABURO SAITO \\ Department of Chemical Engineering, \\ Tohoku University, Sendai 980
}

\begin{abstract}
The solubility of solid hydrocarbons and inorganics (carbon dioxide and hydrogen sulfide) in liquid hydrocarbons was correlated using the modified BWR equation of state of Lee and Kesler and the pseudocritical method to compute the fugacity coefficient of the solute in subcooled liquid. This method requires two binary parameters, $k_{12}$ and $s_{12}$, for each binary pair to be computed from experimental solid-liquid equilibrium data. These parameters are tabulated for a large number of binary systems. The correlation resulting from this investigation will be valuable in the design of cryogenic processes.
\end{abstract}

\section{Introduction}

In recent years increasing attention has been devoted to the thermodynamics of solid-liquid equilibria, due to the practical importance of cryogenic processes such as liquefaction and transportation for natural gas. Preston and Prausnitz ${ }^{22,23)}$ recently presented a review of solid-solubility data and a thermodynamic framework for estimating the solubility of solids in cryogenic liquid solvents. Preston and Prausnitz, and Cheung and Zander ${ }^{13}$ used a modification of the theory of regular solution. Jensen and Kurata ${ }^{6}$, and Hoshino et al. ${ }^{3}$ applied successfully the Wilson equation to solid-liquid equilibria. The Wilson equation has been a good model for solid carbon dioxide solubility in light hydrocarbons, but two additional empirical parameters for each binary system have been required for better agreement with experimental data (Jensen and $\operatorname{Kurata}^{6}$ ). Although for the prediction of vapor-liquid equilibria numerous approaches have been made, based on an equation of state such as the Benedict-Webb-Rubin (BWR) or Redlich-Kwong equations, there are few such approaches for the prediction of solid-liquid equilibria. This is due in part to the lack of a reliable equation of state at low reduced temperatures. In this respect, Lee and Kesler have presented a modified BWR equation of state which is applicable down to 0.3 or below at reduced temperatures. Further, it has been shown in the literature (Reid et $a l^{24}{ }^{24}$ ) that this equation is good for prediction

Received October 9,1978. Correspondence concerning this article should be addressed to S. Saito. H. Masuoka is now at Dept. of Chem. Eng., Hiroshima Univ., Hiroshima 730. of thermodynamic properties such as PVT and enthalpy.

The purpose of this paper is to present a way to correlate and predict solid solubility in liquids using the Lee-Kesler equation of state. Our work is somewhat similar to but more general than that of de Mateo and Kurata ${ }^{21}$, who used a modified Redlich-Kwong equation of state for the correlation of solubility of solid hydrocarbons in liquid methane.

\section{Thermodynamics of Solid-Liquid Equilibria}

Solid-liquid equilibria considered in this study are those for which the solid phase is assumed to be pure solute and the liquid phase is a saturated solution of the solute in the solvent. For such a system, the equation of equilibrium is given by

$$
f_{1}^{o s}=\gamma_{1} x_{1} f_{1}^{o l}
$$

where $f_{1}^{o s}$ is the fugacity of pure solid, $f_{1}^{o l}$ is the fugacity of pure, subcooled liquid, $x_{1}$ is the mole fraction of the solute in the solution, and $\gamma_{1}$ is the activity coefficient of the solute referred to the fugacity, $f_{1}^{o l}$. All of these terms are evaluated at the pressure and temperature of the system. Arranging Eq. (1), solid solubility is expressed as

$$
x_{1}=\frac{f_{1}^{o s} / f_{1}^{o l}}{\gamma_{1}}=\frac{f_{1}^{o s} / f_{1}^{o l}}{\varphi_{1}^{l} / \varphi_{1}^{o l}}
$$

where $\varphi_{1}^{l}$ is the fugacity coefficient of the solute in liquid mixtures, and $\varphi_{1}^{\circ l}$ is the fugacity coefficient of the pure liquid solute. The activity of component 1 can be evaluated by the relation 


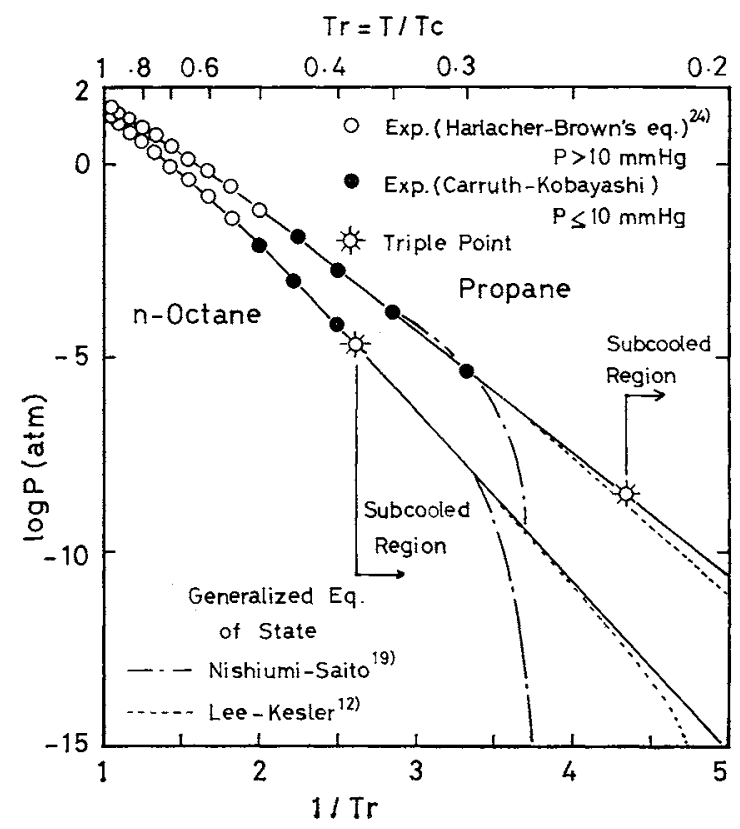

Fig. 1 Comparison of vapor pressures of propane and $n$-octane

$$
\begin{aligned}
\ln \frac{f_{1}^{o s}}{f_{1}^{o l}}= & \frac{\Delta S_{f}}{R}\left(1-\frac{T_{t}}{T}\right)+\frac{\Delta C_{p}}{R}\left(\frac{T_{t}}{T}-1\right) \\
& -\frac{\Delta C_{p}}{R} \ln \frac{T_{t}}{T}-\frac{\Delta V}{R T_{t}}\left(P-P_{t}\right)
\end{aligned}
$$

where $T_{t}$ is the triple-point temperature, $\Delta S_{f}$ is the molar entropy of fusion of the solute, and $\Delta C_{p}$ and $\Delta V$ are the differences between the liquid and solid molar heat capacities and molar volumes respectively. For temperatures not much below the melting temperature of the solute, $T_{m}$, and for normal pressures, Eq. (3) becomes

$$
\ln \frac{f_{1}^{o s}}{f_{1}^{o l}}=\frac{\Delta S_{f}}{R}\left(1-\frac{T_{m}}{T}\right)
$$

Some substances undergo solid-phase transitions from one crystal structure to another. For these solutions, if the temperature of interest is less than the transition temperature, $T_{\mathrm{trans}}$, the expression for the fugacity ratio becomes

$$
\ln \frac{f_{1}^{o s}}{f_{1}^{o b}}=\frac{\Delta S_{f}}{R}\left(1-\frac{T_{m}}{T}\right)+\frac{\Delta S_{\mathrm{trans}}}{R}\left(1-\frac{T_{\mathrm{trans}}}{T}\right)
$$

where $\Delta S_{\text {trans }}$ is the molar entropy of transition. For the temperatures and entropies of fusion and other solid-phase transitions, the extensive tables of Preston et al. ${ }^{22,23)}$ are available. The fugacity coefficients of the pure solute and those of the solute in mixtures were calculated from the equation of state together with the pseudocritical method, as described in the following section.

\section{Generalized BWR Equation of Lee-Kesler, and Its} Application to Mixtures by the Pseudocritical Method

In solid-liquid equilibria the solution temperature is necessarily below the triple-point temperature of the solute. Therefore, the equation of state used to calculate fugacity coefficients must be able to represent the thermodynamic properties of such subcooled liquid. We chose two equations of state which appeared to be promising at lower temperatures: the Lee and $\mathrm{Kesler}^{12}$ three-parameter corresponding-states correlation, and a modification of the BWR equation of Nishiumi and Saito $^{19}$. The Starling modification of the BWR equation (Starling and $\operatorname{Han}^{26)}$ ) was not considered since it was found to be inaccurate at lower reduced temperatures (Nishiumi and Saito ${ }^{19}$ ).

Figure 1 shows a comparison of experimental and calculated vapor-pressure curves for propane and octane. The solid line represents the vapor pressure of the subcooled liquid, obtained by extrapolating the liquid-vapor pressure curve from the triple-point temperature to the solution temperature. In this diagram the calculated vapor-pressure curves of the two equations of state are also plotted. It is shown that both equations have their own limitations in application: for the Nishiumi and Saito equation down to 0.3 at reduced temperature and for the Lee and Kesler equation down to 0.24. At lower temperatures than these, the thermodynamic properties of the subcooled liquid cannot be calculated satisfactorily. The need for calculations at such lower temperatures often arises in the case of solid solubility for heavier hydrocarbons in liquid methane or ethane. Consequently, the Lee and Kesler equation was adopted in this study.

The Lee and Kesler ${ }^{12}$ equation is an extended and improved version of the Pitzer-Curl tables based on a modified BWR equation of state. The compressibility factor of a real fluid is related to properties of a simple fluid $(\omega=0)$ and those of $n$-octane as a reference fluid.

$$
Z=Z^{(0)}+\left(\omega / \omega^{R}\right)\left(Z^{(R)}-Z^{(0)}\right)
$$

where $\omega^{R}=0.3978$. Other thermodynamic functions (fugacity coefficient and enthalpy departure) have been derived from Eq. (6).

In applying the Lee-Kesler equation to mixtures, we used the pseudocritical method. Its use for the calculation of component fugacities and application to phase equilibria has been proposed by a number of investigators, among them Pitzer and Hultgren ${ }^{21}$, Leland et al. ${ }^{13)}$, Leach et al. ${ }^{11)}$, Yorizane et al. ${ }^{27,28)}$, Leyendecker and Gunn ${ }^{14)}$, and Joffe ${ }^{7)}$. However, very little work has been reported concerning the application of the pseudocritical method to solid-liquid equilibria. According to a three-parameter corresponding-states theory ( $\left.\mathrm{Joffe}^{7}\right)$, the fugacity coefficient of component $i$ in the mixture can be written as follows 


$$
\begin{aligned}
\ln -\frac{f_{i}}{P x_{i}}= & \ln \frac{f_{m}}{P}+\frac{n}{T_{c}^{\prime}}\left(-\frac{\partial T_{c}^{\prime}}{\partial n_{i}}\right)_{T, P, n_{j}} \frac{H_{m}-H_{m}^{*}}{R T} \\
& -\frac{n}{P_{c}^{\prime}}\left(\frac{\partial P_{c}^{\prime}}{\partial n_{i}}\right)_{T, P, n_{j}}\left(Z_{m}-1\right) \\
& +n\left(\frac{\partial \omega_{m}}{\partial n_{i}}\right)_{T, P, n_{j}}\left(\frac{\partial \ln \left(f_{m} / P\right)}{\partial \omega_{m}}\right)_{T_{r^{\prime}, P_{r^{\prime}}}}
\end{aligned}
$$

Although various sets of mixing rules for calculating the pseudocritical constants have been proposed, the following set of mixing rules (van der Waals' onefluid theory) was adopted.

$$
\left.\begin{array}{l}
V_{c}^{\prime}=\sum_{i} \sum_{j} x_{i} x_{j} V_{c i j} \\
T_{c}^{\prime}=\sum_{i} \sum_{j} x_{i} x_{j} V_{c i j} T_{c i j} / V_{c}^{\prime} \\
Z_{c i}=P_{c i} V_{c i} / R T_{c i} \\
Z_{c}^{\prime}=\sum_{i} x_{i} Z_{c i} \\
P_{c}^{\prime}=Z_{c}^{\prime} R T_{c}^{\prime} / V_{c}^{\prime} \\
\omega_{m}=\sum x_{i} \omega_{i} \\
V_{c i j}=\left(1-S_{i j}\right)\left(V_{e i}^{1 / 3}+V_{c j}^{1 / 3}\right)^{3} / 8 \\
T_{c i j}=\left(1-k_{i j}\right) \sqrt{T_{e i} T_{c j}}
\end{array}\right\}
$$

where $k_{i j}$ and $s_{i j}$ are parameters determined from binary solid-liquid equilibrium data.

Derivatives of pseudocriticals required in Eq. (7) are as follows:

$$
\begin{aligned}
\frac{n}{V_{c}^{\prime}}\left(\frac{\partial V_{c}^{\prime}}{\partial n_{k}}\right)= & \frac{2}{V_{c}^{\prime}}\left[\sum_{i} x_{i} V_{c i k}-V_{c}^{\prime}\right] \\
\frac{n}{T_{c}^{\prime}}\left(\frac{\partial T_{c}^{\prime}}{\partial n_{k}}\right)= & \frac{2}{T_{c}^{\prime} V_{c}^{\prime}} \sum_{i} x_{i} V_{c i k}\left(T_{c i k}-T_{c}^{\prime}\right) \\
\frac{n}{P_{c}^{\prime}}\left(\frac{\partial P_{c}^{\prime}}{\partial n_{k}}\right)= & \frac{n}{T_{c}^{\prime}}\left(\frac{\partial T_{c}^{\prime}}{\partial n_{k}}\right)-\frac{n}{V_{c}^{\prime}}\left(\frac{\partial V_{c}^{\prime}}{\partial n_{k}}\right) \\
& +\frac{n}{Z_{c}^{\prime}}\left(\frac{\partial Z_{c}^{\prime}}{\partial n_{k}}\right) \\
\frac{n}{Z_{c}^{\prime}}\left(\frac{\partial Z_{c}^{\prime}}{\partial n_{k}}\right)= & \frac{1}{Z_{c}^{\prime}}\left[Z_{c k}-Z_{c}^{\prime}\right] \\
n\left(\frac{\partial \omega_{m}}{\partial n_{k}}\right)= & \omega_{k}-\omega_{m}
\end{aligned}
$$

The critical properties used throughout this work were taken from Reid et al. ${ }^{24)}$ and the acentric factors were taken from Passut and Danner ${ }^{20)}$.

\section{Solubility Calculations and Correlation of Solid- Liquid Equilibria}

The solubility of component 1 in component 2 was calculated by solving Eqs. (2) to (10) by an iterative procedure. Throughout this work, Eq. (4) or (5) was used instead of Eq. (3) for the expression of the activity of component 1 , because calculations with Eq. (3) did not lead to appreciable improvements. The solubility, in general, is calculated at the system temperature by a trial-and-error procedure. This pro-

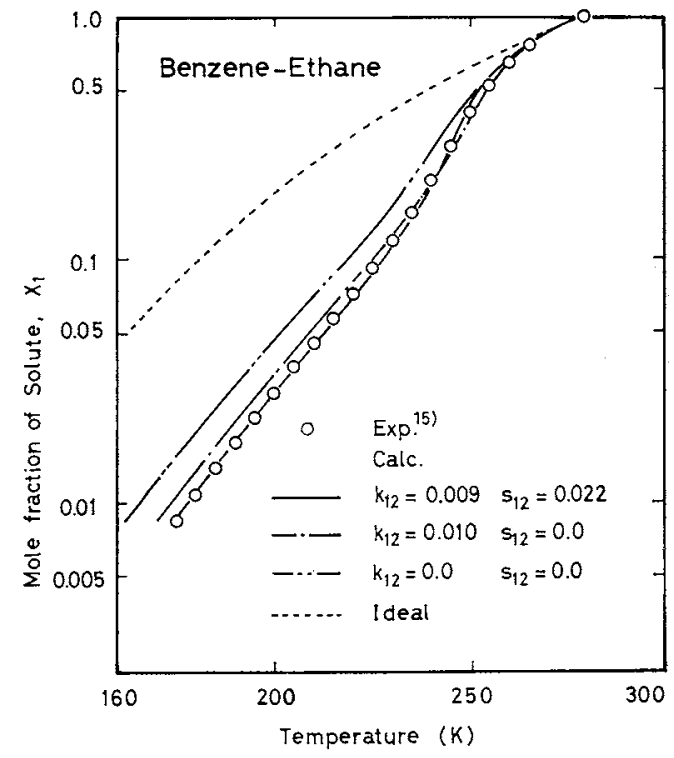

Fig. 2 Solubility of benzene in ethane

cedure, however, is undesirable for systems in which immiscible liquids form or solid solubility varies greatly with small temperature changes, because in such cases the calculations tend not to converge. The pressure and the liquid mole fractions were selected as the independent, known variables; the program calculates the equilibrium temperature. Successive estimates of the temperature were made using a Newtonian interpolation and extrapolation technique. The pressure used in these calculations was that reported in the experimental data, except for the system where the experimental pressure was not reported, in which the vapor pressure of pure solvent at the system temperature was used. We calculated the solubility in three ways: first, assuming $k_{12}=s_{12}=0$; second, using $s_{12}=0$ and an empirical $k_{12}$ which best reproduces the experimental solubility data; third, using an empirical $k_{12}$ and $s_{12}$. Some typical results are shown in Figs. 2 to 7 .

Figure 2 shows the results for the benzene-ethane system $^{15)}$. The broken line represents ideal solubility. The results with $k_{12}=0.010$ and $s_{12}=0$ intersect the experimental values and cannot reproduce them adequately, whereas the results with two parameters $\left(k_{12}=0.009\right.$ and $\left.s_{12}=0.022\right)$ can satisfactorily reproduce the experiment. Similar results were obtained for other systems. Then two binary parameters $\left(k_{12}\right.$ and $\left.s_{12}\right)$ for each system were determined empirically in the subsequent calculations. Table 1 presents $k_{12}$ and $s_{12}$ values for several binary systems determined from the solid-solubility calculations using data taken from the literature. Most $k_{12}$ and $s_{12}$ values are near zero. However, even a small variation from zero can appreciably affect estimated properties.

Figure 3 shows the results for solubility of three $n$ - 


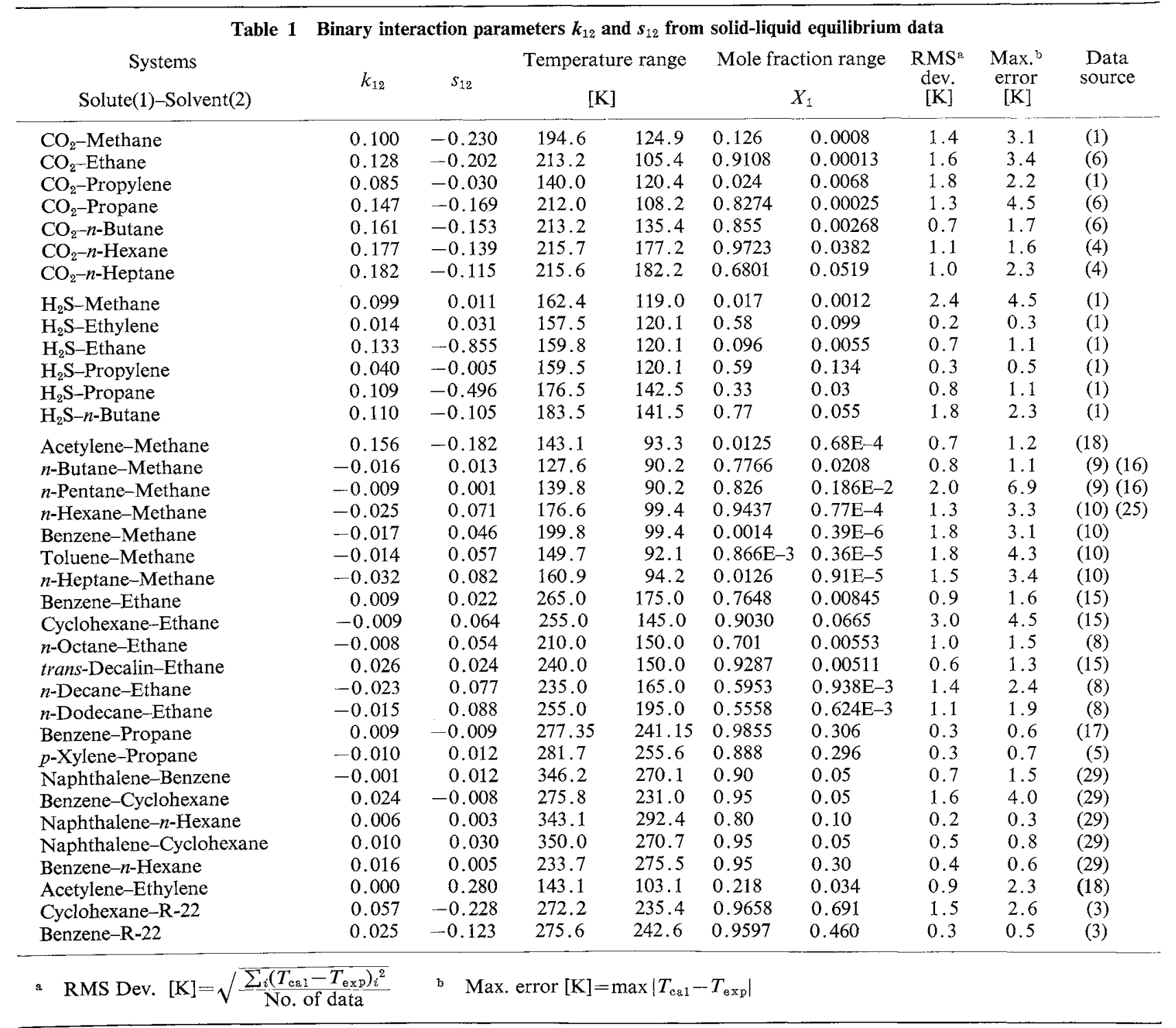

alkanes in ethane ${ }^{8)}$. These systems exhibit nearly ideal behavior, and as nonsimilarities among constituents become large, deviations from ideal behavior also become increasingly large.

Figure 4 shows the results for the benzene-cyclohexane system ${ }^{29}$ which forms a eutectic mixture. As shown in this diagram, we can represent the solubility diagram of the entire binary system with one set of binary parameters. Figure 5 presents the results for the carbon dioxide- $n$-heptane system ${ }^{4}$. In this system immiscible liquids form at high carbon dioxide concentrations, and a small change of temperature results in a large change of solubility. This diagram also shows correlation of the Wilson equation (3-parameter form), and Scatchard-Hamer equation (2-pa rameter form). Among the three equations tested, both the Wilson equation in 3-parameter form and this work in 2-parameter form gave better results.

The result for the $n$-hexane-methane system ${ }^{10,25)}$ is shown in Fig. 6. This system has already been cor- related using the Redlich-Kwong equation of state by de Mateo and Kurata ${ }^{2}$. But at higher temperatures their prediction was in great error, perhaps because of divergence of iterative calculations. Their divergence may be attributed to the calculation procedure performed at constant temperature. In the present work, however, this was improved where calculations were performed at constant compositions as described previously. The result for the benzenemethane system ${ }^{10)}$ is shown in Fig. 7. This diagram indicates that the effect of pressure on solubility is manifested near the solvent critical temperature. Figures 8 and 9 present $k_{12}$ and $s_{12}$ as a function of the ratio $V_{c i} / V_{c j}$. These diagrams show the results for mixtures of carbon dioxide with hydrocarbons and those for mixtures of hydrocarbons with hydrocarbons. These correlations serve to estimate parameters $\left(k_{12}\right.$ and $s_{12}$ ) for binaries where insufficient experimental information is at hand. No results for the $\mathrm{CO}_{2}-$ propylene system or for systems containing $\mathrm{H}_{2} \mathrm{~S}$ were 


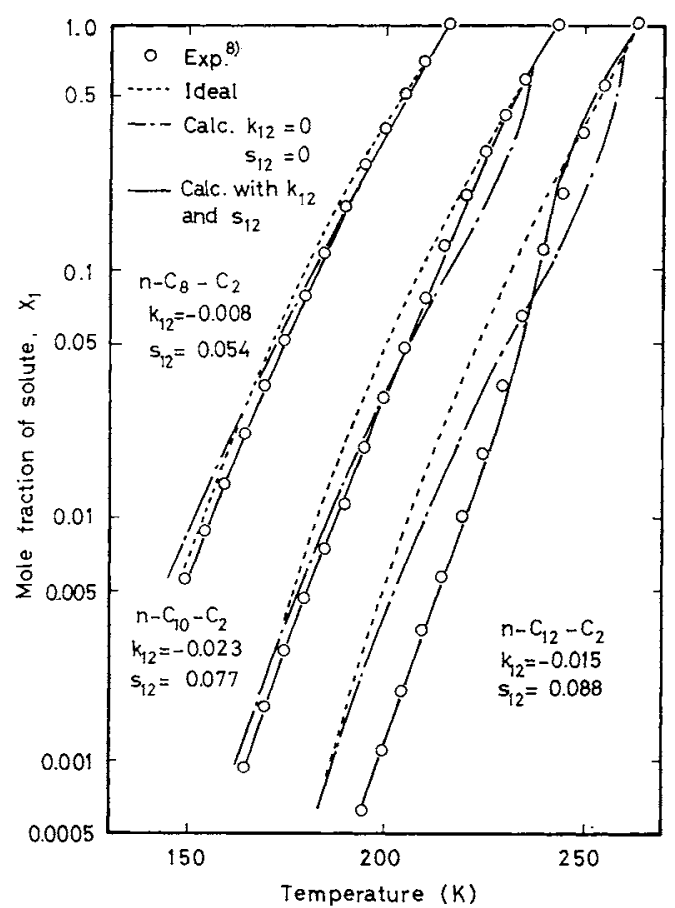

Fig. 3 Solubility of $n$-alkanes in ethane

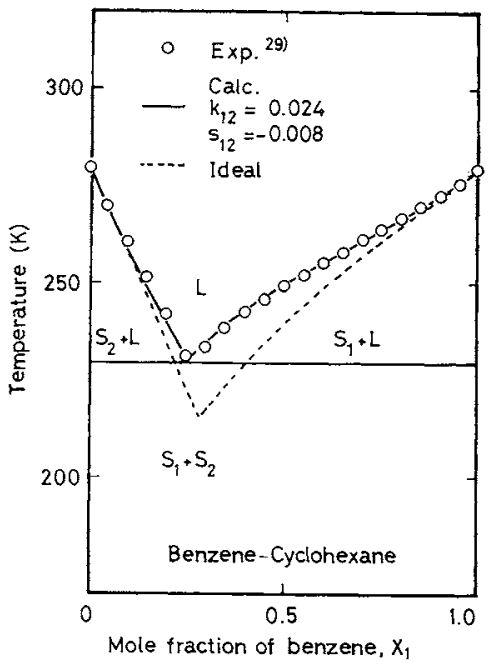

Fig. 4 Solid-liquid equilibria for benzene-cyclohexane system

included in these diagrams, because smoothed correlations were not obtained for these systems. One of the reasons for this defect seems to be that for these systems experimental information is of limited quantity.

\section{Conclusions}

The equation of state of Lee-Kesler together with the pseudocritical method can correlate the solubility of solids in liquids with sufficient accuracy for most technical purposes. The correlation resulting from this investigation will be valuable in the design of cryogenic processes.

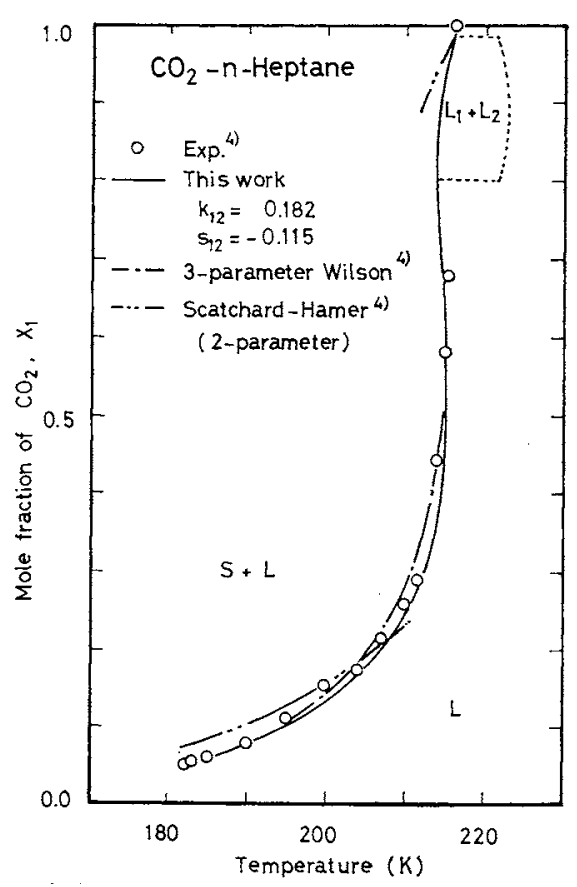

Fig. 5 Solubility of carbon dioxide in $n$-heptane

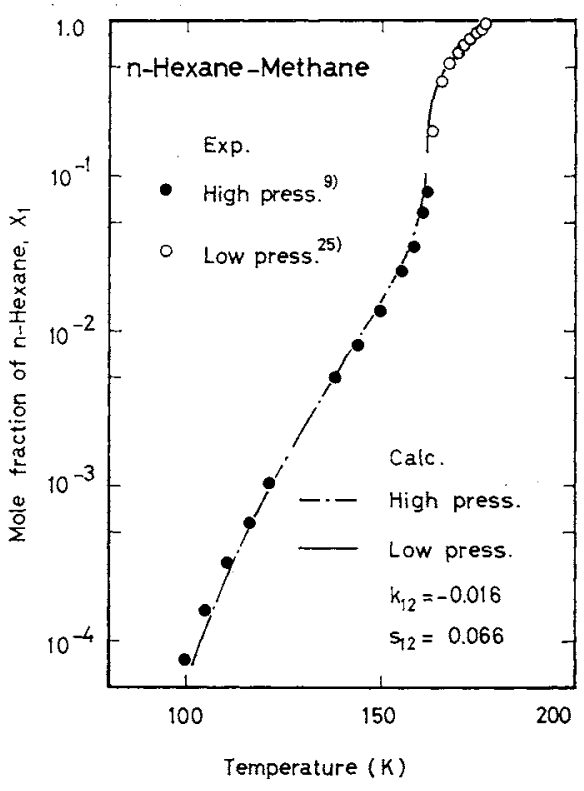

Fig. 6 Solubility of $n$-hexane in methane

\begin{tabular}{|c|c|c|}
\hline \multicolumn{3}{|c|}{ Nomenclature } \\
\hline$f$ & $=$ fugacity & [atm] \\
\hline$H$ & $=$ molar enthalpy & {$\left[\mathrm{cal} \cdot \mathrm{mol}^{-1}\right]$} \\
\hline$k_{12}$ & $\begin{array}{l}=\text { binary interaction constant defined in } \\
\text { Eq. (9) }\end{array}$ & {$[-]$} \\
\hline$n$ & $=$ total amount of substance & [mol] \\
\hline$P$ & - pressure & [atm] \\
\hline$R$ & $\begin{aligned}= & \text { gas constant, } 1.9872 \\
& \text { gas constant, } 82.054\end{aligned}$ & $\left.\cdot \mathrm{mol}^{-1} \cdot \mathrm{K}^{-1}\right]$ \\
\hline$S$ & $=$ molar entropy & $\left.\cdot \mathrm{mol}^{-1} \cdot \mathrm{K}^{-1}\right]$ \\
\hline$s_{12}$ & $\begin{array}{l}=\text { binary interaction constant defined in } \\
\text { Eq. (9) }\end{array}$ & {$[-]$} \\
\hline$T$ & $=$ temperature & {$[\mathrm{K}]$} \\
\hline$V$ & $=$ molar volume & {$\left[\mathrm{cc} \cdot \mathrm{mol}^{-1}\right]$} \\
\hline
\end{tabular}

\section{Nomenclature}

$f \quad=$ fugacity

atm]

$-1$

mol]

atm]

$\mathrm{atm} \cdot \mathrm{mol}^{-1} \cdot \mathrm{K}^{-1]}$ $\left[\mathrm{cal} \cdot \mathrm{mol}^{-1} \cdot \mathrm{K}^{-1}\right.$ ]

[K] 


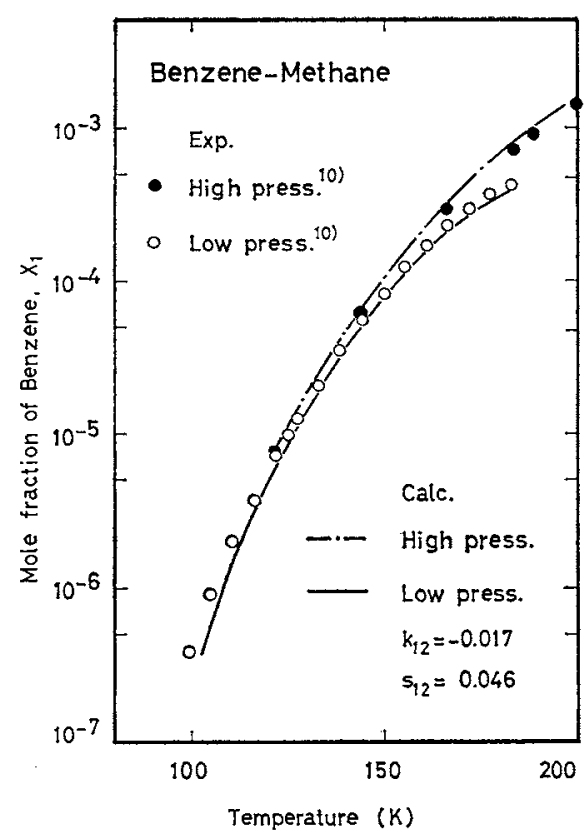

Fig. 7 Solubility of benzene in methane

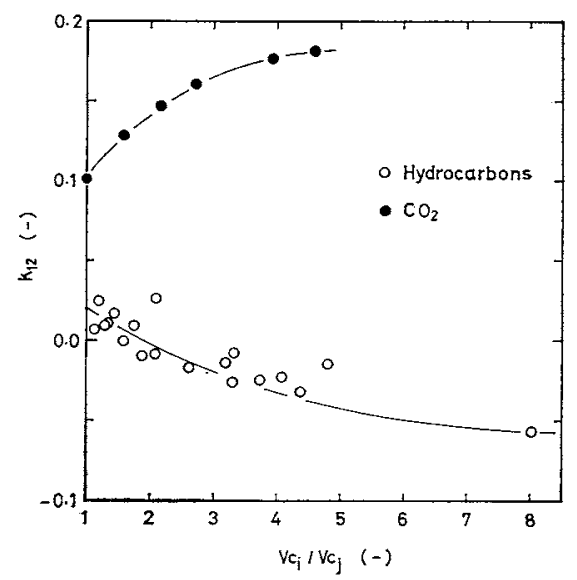

Fig. 8 Correlation of binary interaction parameters, $\boldsymbol{k}_{12}$

$V_{r} \quad=P_{\mathrm{e}} V / R T_{\mathrm{c}}$

$x=$ mole fraction in liquid

$Z=$ compressibility factor

$\gamma=$ activity coefficient

$\omega \quad=$ acentric factor

$[-]$

〈Superscripts and subscripts〉

$c \quad=$ critical property

$f=$ fusion

$i, j, k=$ components in solution

$l=$ liquid

$m \quad=$ normal melting point

$r \quad=$ reduced property

$s \quad=$ solid

trans $=$ transition point

$(R) \quad=$ reference fluid

(0) $\quad=$ simple fluid

(1) = deviation function of the Lee-Kesler correlation

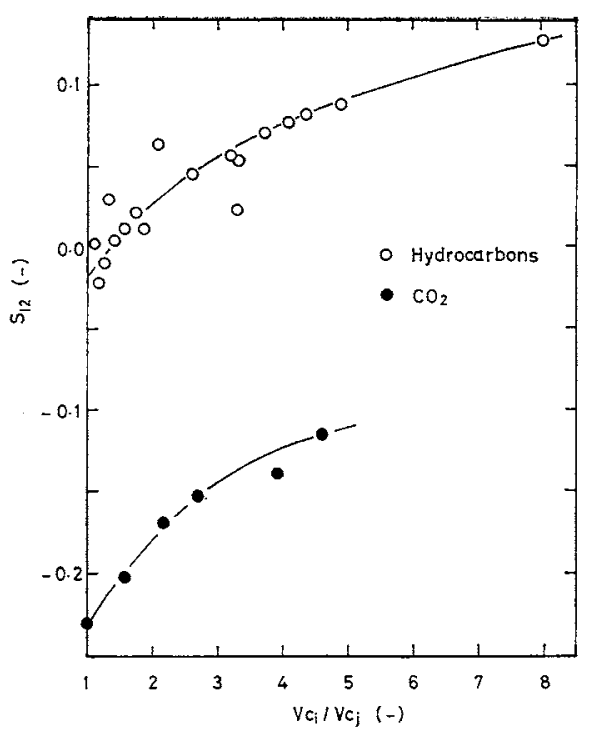

Fig. 9 Correlation of binary interaction parameters, $s_{12}$

$$
\begin{aligned}
& =\text { solute } \\
& =\text { solvent } \\
& =\text { pseudocritical property of a mixture } \\
& =\text { ideal gas property }
\end{aligned}
$$

\section{Literature Cited}

1) Cheung, H. and E. H. Zander: Chem. Eng. Progr., Symp. Ser., 64 (88), 34 (1968).

2) de Mateo, A. and F. Kurata: Ind. Eng. Chem., Process Des. Dev., 14, 137 (1975).

3) Hoshino, D., K. Yagi, K. Nagahama and M. Hirata: $J$. Chem. Eng. Japan, 10, 262 (1977).

4) Im, U. K. and F. Kurata: J. Chem. Eng. Data, 16, 412 (1971).

5) Ishizuka, I., Y. Arai and S. Saito: Preprint of the 11th Autumn Meeting of The Soc. of Chem. Engrs., Japan, p. 207 (1977).

6) Jensen, R. H. and F. Kurata: AIChE J., 17, 357 (1971).

7) Joffe, J.: Ind. Eng. Chem., Fundam., 15, 298 (1976).

8) Kohn, J. P., K. D. Luks and P. H. Liu: J. Chem. Eng. Data, 21, 360 (1976).

9) Kuebler, G. P. and C. McKinley: Cryogenic Engineering Conference, Kingston, Ontario, Canada, Paper E-7 (1975).

10) Kuebler, G. P. and C. McKinley: Advances in Cryogenic Engineering, Vol. 19, p. 320, Plenum Press, New York (1974).

11) Leach, J. W., P. S. Chappelear and T. W. Leland: $A I C h E$ $J ., 8,482$ (1962).

12) Lee, B. I. and M. G. Kesler: ibid., 21, 510 (1975).

13) Leland, T. W., P. S. Chappelear and B. W. Gamson: ibid., 8, 482 (1962).

14) Leyendecker, W. R. and R. D. Gunn: ibid., 18, 188 (1972).

15) Liu, P. H., K. D. Luks and J. P. Kohn: J. Chem. Eng. Data, 22, 220 (1977).

16) Morlet, J.: Revue de l'Institut Français du Pétrole, 18, 127 (1963).

17) Nagahama, K.: '75 Int. Chem. Plant Eng. Congress, Session A-III, Tokyo, p. 33 (1975).

18) Neumann, A. and R. Mann: Chem. Ing. Techn., 41, 708 (1969).

19) Nishiumi, H. and S. Saito: J. Chem. Eng. Japan, 8, 356 
(1975).

20) Passut, C. A. and R. P. Danner: Ind. Eng. Chem., Process Des. Dev., 12, 365 (1973).

21) Pitzer, K. S. and G. O. Hultgren: J. Am. Chem. Soc., 80, 4793 (1958).

22) Preston, G. T., E. W. Funk and J. M. Prausnitz: J. Phys. Chem., 75, 2345 (1971).

23) Preston, G. T. and J. M. Prausnitz: Ind. Eng. Chem., Process Des. Dev., 9, 264 (1970).

24) Reid, R. C., J. M. Prausnitz and T. K. Sherwood: "The Properties of Gases and Liquids", 3rd ed., McGraw-Hill (1977).
25) Shim, J. and J. P. Kohn: J. Chem. Eng. Data, 7, 3 (1962).

26) Starling, K. E. and M. S. Han: Hydro. Proc., 51 (5), 129 (1972).

27) Yorizane, M., S. Yoshimura, H. Masuoka and A. Toyama: Proceeding of the 1st International Cryogenic Engineering Conference, Tokyo and Kyoto, Japan (1967).

28) Yorizane, M. and Y. Miyano: AIChE J., 24, 181 (1978).

29) Yoshida, K., I. Yamada and H. Machii: Kagaku Kōgaku, 32, 53 (1968).

(Presented at the 43rd Annual Meeting of The Soc. of Chem. Engrs., Japan, at Nagoya, 1978.)

\title{
CORRELATION FOR DYNAMIC HOLDUP IN PACKED BEDS WITH COCURRENT GAS-LIQUID DOWNFLOW
}

\author{
AKINORi MATSUURA and TAKashi AKEHATA \\ Department of Environmental Chemistry and Engineering, \\ Tokyo Institute of Technology, Yokohama 227 \\ TAKASHI SHIRAI \\ Research Laboratory of Resources Utilization, \\ Tokyo Institute of Technology, Yokohama 227
}

\begin{abstract}
An equation for dynamic holdup of cocurrent gas-liquid downflow in packed beds was developed on the basis of models in which the interactions among liquid holdup, pressure gradient and liquid flow rate for the gravity-viscosity and the gravity-inertia regimes were taken into account. The dynamic holdup data for beds of glass spheres $(0.12-0.43 \mathrm{~cm}$ in diameter) with air-water flow were correlated well, in terms of static pressure gradient and total holdup together with the operating variables, by the equation $h \phi=13.5\left[\left(\operatorname{Re}_{l}\right) /\left(G a_{l}^{\dagger}\right)\right]^{1 / 3}+1.20\left(R e_{t}\right)\left(G a_{l}^{\dagger}\right)^{-1 / 2}$

where $\quad \boldsymbol{R e}_{l}=\boldsymbol{G}_{l} \boldsymbol{d}_{p} / \boldsymbol{\mu}_{l}$ and $\boldsymbol{G} \boldsymbol{a}_{l}^{\dagger}=\boldsymbol{\rho}_{l}^{2} \boldsymbol{g} \boldsymbol{d}_{p}{ }^{3}\left\{\mathbf{1}-\left(\boldsymbol{g}_{c} / \boldsymbol{\rho}_{l} \boldsymbol{g h}\right)(\boldsymbol{d p} / \boldsymbol{d z})\right\} / \boldsymbol{\mu}_{l}^{2}$.

A procedure was also shown for evaluating the dynamic and the total holdups and the static pressure gradient using only such operating variables as particle diameter and superficial velocities of gas and liquid.
\end{abstract}

\section{Introduction}

Liquid holdup may well be considered as one of the basic quantities for design calculation and operation of packed-bed reactors with cocurrent gas-liquid downflow. Holdup has been shown to have a direct influence on mass transfer ${ }^{4}$, heat transfer ${ }^{11,14}$, pressure $\operatorname{loss}^{9}$ and axial dispersion of liquid ${ }^{8}$. Many investigators have measured holdup and have produced empirical equations, in which various types of parameters were employed, such as the flow parameter $\chi$ of Lockhart and Martinelli ${ }^{7,13}$, dimensionless numbers such as Reynolds and Galileo numbers ${ }^{12,13,15)}$, the mass velocity and Reynolds number ratios between gas and liquid ${ }^{3,17,18)}$ and parameters derived from

Received November 9, 1978. Correspondence concerning this article should be addressed to A. Matsuura. theoretical considerations on gas and liquid flows in packed beds ${ }^{2,5,6)}$. Due to the complex gas-liquid interaction, most correlations are applicable only in a few restricted regimes, and some investigators ${ }^{13,17}$ ) correlated their experimental data in two separate equations depending on the flow pattern or the gasliquid interaction regimes. Buchanan ${ }^{11}$ correlated the experimental data of the operating holdup in terms of the two dimensionless numbers $\left(R e_{l} / G a_{l}\right)^{1 / 3}$ and $\left(\operatorname{Re}_{l} / G a_{l}{ }^{1 / 2}\right)$, which were derived theoretically on the basis of the momentum and the energy balances in the gravity-viscosity model and the gravity-inertia model, respectively. Buchanan's equation seems to be generalized and to be applicable in a wider range of liquid flow rates. The two parameters involved in Buchanan's correlation were examined for correlating the dynamic holdup data ${ }^{8)}$ of cocurrent gas-liquid down- 